\title{
Laminated intestinal calculi - A rare complication of Crohn's disease
}

\author{
Hugh J FreEman mD, ANDREW SEAl mD, DAVID Li mD
}

HJ FREEMAN, A SEAL, D LI. Laminated intestinal calculi - A rare complication of Crohn's disease. Can J Gastroenterol 1995;9(1):13-16. A 59-year-old male with a 36-year history of Crohn's disease and repeated resections for small intestinal strictures developed anemia and symptoms of an intermittent partial bowel obstruction. Barium studies showed recurrent small intestinal strictures as well as filling defects in a dilated loop proximal to a stenosed segment. Subsequent abdominal films and a computed tomographic study suggested laminated radiopaque calculi with peripheral calcification in the dilated small intestinal loop. Resection of the strictured segment confirmed the presence of intestinal enterolithiasis.

Key Words: Abdominal calcification, Crohn's disease, Enteric stones, Enterolithiasis, Inflammatory bowel disease, Small intestinal strictures

\section{Calculs intestinaux lamellaires : rare complication de la maladie de Crohn}

RÉSUMÉ : Un homme de 59 ans atteint depuis 36 ans d'une maladie de Crohn et ayant subi de multiples résections intestinales pour strictures a développé de l'anémie et des symptômes d'obstruction intestinale intermittente. Les épreuves barytées ont révélé des strictures récurrentes au niveau de l'intestin grêle, de même que des anomalies de remplissage dans une anse dilatée avoisinant un segment sténosé. Les clichés abdominaux subséquents et un examen tomographique ont suggéré la présence de calculs lamellaires radio-opaques, avec calcification périphérique dans l'anse dilatée du grêle. La résection du segment porteur de strictures a confirmé la présence d'entérolithiase intestinale.

Departments of Medicine (Gastroenterology), Surgery and Radiology, University of British Columbia, Vancouver, British Columbia

Correspondence and reprints: Dr Hugh Freeman, ACU F-137, Gastroenterology, University Hospital (UBC Site), 2211 Wesbrook Mall, Vancouver, British Columbia

V6R 3V8. Telephone (604) 822-7216

Received for publication March 27, 1994. Accepted May 27, 1994
Thtestinal FOREIGN BODIES MAY

be either exogenous or endogenous (1). Endogenous foreign bodies may be primary and formed within the intestinal tract (eg, enteroliths), or secondary and enter the gastrointestinal tract from adjacent structures (eg, gallstones). Enteroliths may be further subdivided into a false type formed from clumping of insoluble ingested material or by inspissation of bowel contents (eg, phytobezoars, trichobezoars, fecoliths), or a true type formed from precipitation of substances present in the lumen (eg, bile or mineral salts, such as calcium) (1).

Laminated radiopaque intestinal calculi detected during the course of clinical evaluation may be associated with congenital (eg, Meckel's diverticulum, ileal duplication cyst) or acquired conditions (eg, anastomotic or postinflammatory strictures, such as Crohn's disease of the small intestine). in both, local stasis of the intestinal contents is critical to stone development (1).

Although small intestinal strictures are extremely common in Crohn's disease, enterolithiasis is very rare, being recorded to date in only 14 patients 


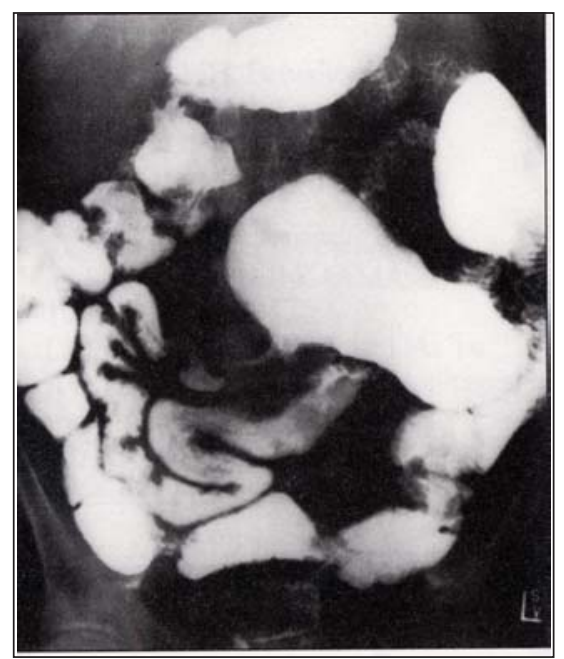

Figure 1) Barium radiograph of the small intestine, May 1992, showing small bowel stricture with dilated loop of small intestine; within the dilated small bowel loop, a filling defect is seen

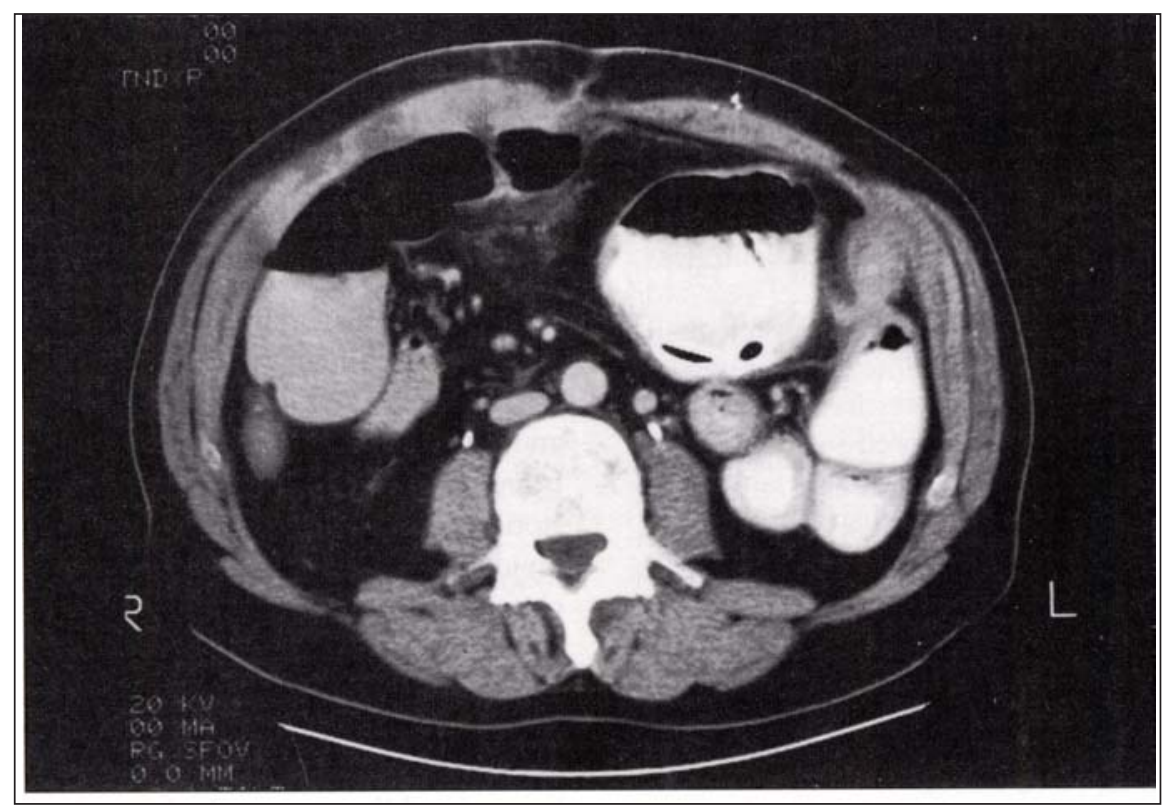

Figure 4) Computed tomographic image from September 1992 showing multiple thickened small intestine with a single widely dilated intestinal loop containing the two calculi

(2-10). Detection is important, however, since intestinal calculi may be associated with obstruction, bleeding, refractory anemia and, in rare instances, perforation.

\section{CASE PRESENTATION}

A 51-year-old male was initially referred for assessment of Crohn's disease in November 1984. A diagnosis of Crohn's disease involving the small intestine was first established in 1956 in the United States followed by repeated

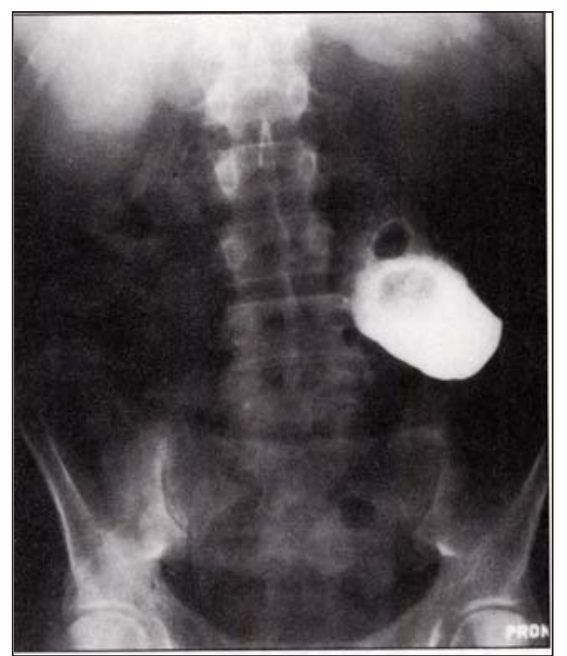

Figure 2) Delayed film showing a persistent collection of barium in a dilated small bowel loop 24 h later with two persisting filling defects

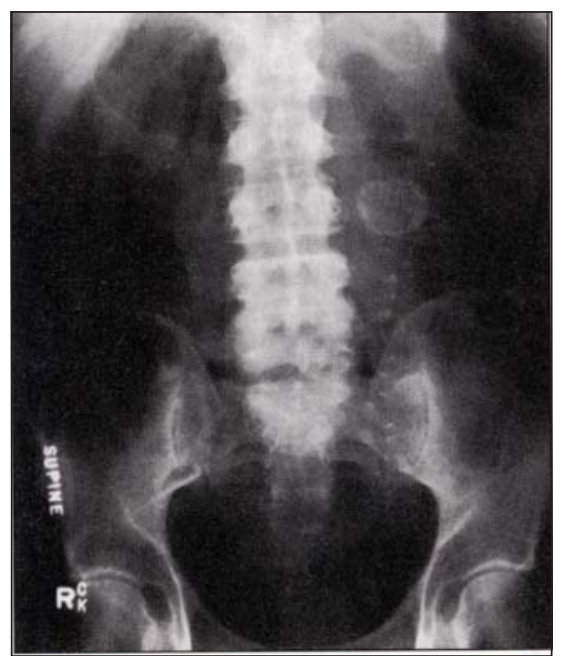

Figure 3) Abdominal film in September 1992 showing two intestinal calculi with peripheral lamination

treated with sulfasalazine. Although he remained virtually asymptomatic, barium studies of the upper and lower gastrointestinal tract in 1974 revealed a jejunal stricture with small bowel dilation proximal to this narrowed segment.

In 1984, abdominal pain recurred. Laboratory studies, including a hemoglobin, white blood cell and platelet counts, liver chemistry tests, sedimentation rate, serum iron, folic acid and vitamin $\mathrm{B}_{12}$, were normal. Urinalysis was normal. Colonoscopy and biopsies were normal. Barium studies revealed similar changes to 1974; in addition, thickening and nodularity of the mucosa in the descending duodenum were now evident. Sulfasalazine treatment was continued and the patient's symptoms appeared to resolve with a lactose-free diet. Clinical evaluations and blood tests done semi-annually over the next eight years were normal. In 1990, abdominal pain recurred temporarily; barium studies now showed a normal duodenum as well as previously defined strictures but no new radiological findings and, following this study, his symptoms spontaneously resolved.

In May 1992, the patient was reevaluated because of recurrent and severe abdominal pain. Laboratory studies revealed (normal range in brackets): hemoglobin, $126 \mathrm{~g} / \mathrm{L}$ (140 to 180 ), mean cell volume, $76 \mathrm{fL}$ (82 to 98 ), 


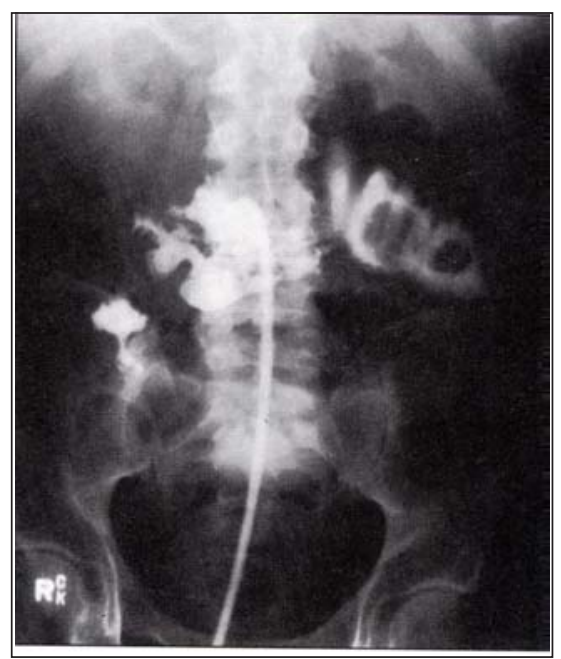

Figure 5) Fistulogram demonstrating communication of the fistulous tract with the small intestine containing two filling defects

white blood cell count, $7.3 \times 10^{9} / \mathrm{L}(4.0$ to 11.0 ), serum ferritin, $16 \mu \mathrm{g} / \mathrm{L}$ (18 to 250), serum iron, $6 \mu \mathrm{mol} / \mathrm{L}$ ( 7 to 23 ) and serum iron saturation 0.09 (0.20 to 0.55). A barium study revealed a markedly dilated loop of small bowel proximal to a stricture; in the dilated loop, a filling defect was seen (Figure 1). In delayed films done $24 \mathrm{~h}$ later, residual barium was seen in the dilated loop; two radiolucent and mobile filling defects were clearly seen (Figure 2). Following treatment with oral 5-aminosalicylic acid his pain subsided.

In September 1992, pain recurred in the patient's right upper quadrant with development of erythema and swelling over the right rectus sheath. Within $24 \mathrm{~h}$ a small amount of purulent drainage was seen from an apparent fistula. Except for a hemoglobin level of 112 $\mathrm{g} / \mathrm{L}$, other laboratory studies, including a white blood cell count, were normal. An abdominal film revealed two structures with faint peripheral calcification (Figure 3). An abdominal computed tomography scan showed a thickened right rectus muscle with an irregular $3 \mathrm{~cm}$ fluid collection typical of an abscess. A dilated segment of small bowel was present with two peripherally calcified structures (Figure 4). After initiation of parenteral nutrition and intravenous antibiotics, a fistulogram demonstrated communication with the

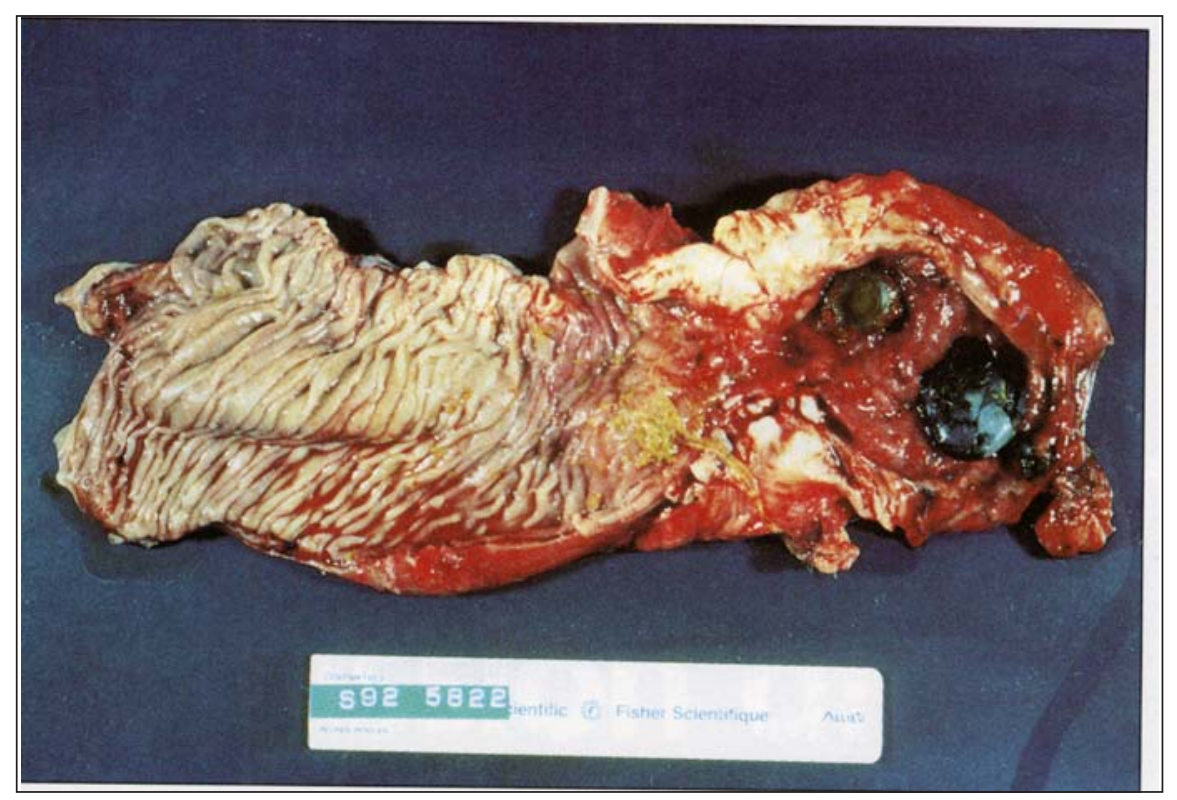

Figure 6) Resected small intestine showing typical features of Crohn's disease with intestinal calculi

small intestine; again, the two filling defects were seen (Figure 5). After failure of the fistula to heal with conservative management, a small intestinal resection was done including the enterocutaneous fistula. The resected segment of small bowel revealed characteristic features of Crohn's disease with two enteroliths (Figure 6).

\section{DISCUSSION}

Primary enterolithiasis or intestinal calculi are rare but may be a clue to occult intestinal disease and must be differentiated from secondary calculi that originate elsewhere and subsequently enter or erode into the gastrointestinal tract, such as gallstones. Formation of intestinal calculi requires the proper chemical milieu within the lumen of the intestine $(1,8,10)$ as well as conditions that lead to local stasis, as may be observed with congenital abnormalities such as a Meckel's diverticulum or a duplication cyst of the distal ileum. Occasionally, acquired causes of intestinal stasis may be responsible, including postoperative or postinflammatory strictures such as occurs in Crohn's disease. Although our patient had longstanding Crohn's disease, the initial detection of intestinal calculi (eg, with abdominal films) in a new patient should lead to further studies including barium radiographs to exclude unrcog- nized intestinal disease, including Crohn's disease. Enteroliths are always clinically significant because they may represent the first clue to an occult small bowel diverticulum or a stenosing lesion. Misinterpretation as biliary or urinary tract calculi or as innocuous concretions in the peritoneal or extraperitoneal spaces could result in inappropriate treatment (1).

To date, there have been 14 patients reported in the literature with Crohn's disease and a clinical course that has been complicated with intestinal calculi (1-10). Usually, but not exclusively, these are detected in the small intestine. Single or multiple calculi with smooth or faceted borders have been described, usually, as in our patient, in a chronically dilated small bowel loop proximal to a stricture. In some patients, intestinal calculi may have been primarily responsible for the obstructing symptoms along with chronic or recurrent blood loss and iron deficiency anemia that has been refractory or difficult to manage (10). In very rare patients with Crohn's disease and intestinal calculi, the presentation has been dramatic with perforation (5); thus, while rare, the potentially serious outcome of intestinal stones deserves emphasis. In all patients described with Crohn's disease and intestinal calculi, the average duration between the 
clinical onset of Crohn's disease and the detection of enterolithiasis was prolonged, usually over a decade, range five to 33 years (10). In our patient, who had calculi detected in 1992, the Crohn's disease was first established elsewhere 36 years earlier in 1956.

Although stasis appears to be a critical factor in the pathogenesis of these stones, their chemical composition is believed to depend on the site of forma-

\section{REFERENCES}

1. Atwell JD, Pollock AV. Intestinal calculi. Br J Surg 1960;47:367-74.

2. Katz I, Fischer RM. Enteroliths complicating regional enteritis. A report of two cases. Am J Roentgenol 1957;78:653-61.

3. Brettner A, Euphrat EJ. Radiological significance of primary enterolithiasis. Radiology 1970;94:283-8.

4. Johnson CK, Levagood FB. Regional enteritis: enteroliths causing tion along the length of the small intestine as well as the $\mathrm{pH}$ of the intestinal chyme at the location of the stones. The relatively lower $\mathrm{pH}$ of the duodenum and proximal jejunum apparently favours deposition of bile acids that tend to be radiolucent on plain abdominal radiographs. In contrast, ileal stones usually contain mineral salts that tend to precipitate in the more alkaline environment of the distal small intestine. These calculi tend to be

intermittent obstruction. Arizona Med 1975;32:94-6.

5. Zeit RM. Enterolithiasis associated with ileal perforation in Crohn's disease. Am J Gastroenterol 1979;72:662-4.

6. Javors BR, Bryk D. Enterolithiasis: a report of four cases. Gastrointest Radiol 1983;8:359-62.

7. Schut JM, Mallens WMC. Calcified enteroliths in regional enteritis. Diagn Imaging Clin Med 1986;55:146-50.

8. Paige ML, Ghahremani GG, Brosnan laminated and more radiopaque; a variety of minerals such as calcium carbonate, calcium oxalate and, rarely, magnesium or even barium sulphate may be present $(1,8,10)$. The possible role that dietary factors, medications such as antacids or investigative barium studies may play in stone development is not known.

JJ. Laminated radiopaque enteroliths: diagnostic clues to intestinal pathology. Am J Gastroenterol 1987;82:432-7.

9. Harvey IC, White HJO. Stones, Crohn's disease and Meckel's diverticulum. Br Med J 1976;2:1107.

10. Yuan JG, Sachar DB, Koganei K, Greenstein AJ. Enterolithiasis, refractory anemia, and strictures of Crohn's disease. J Clin Gastroenterol 1994;18:105-8. 


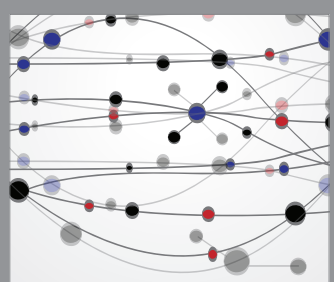

The Scientific World Journal
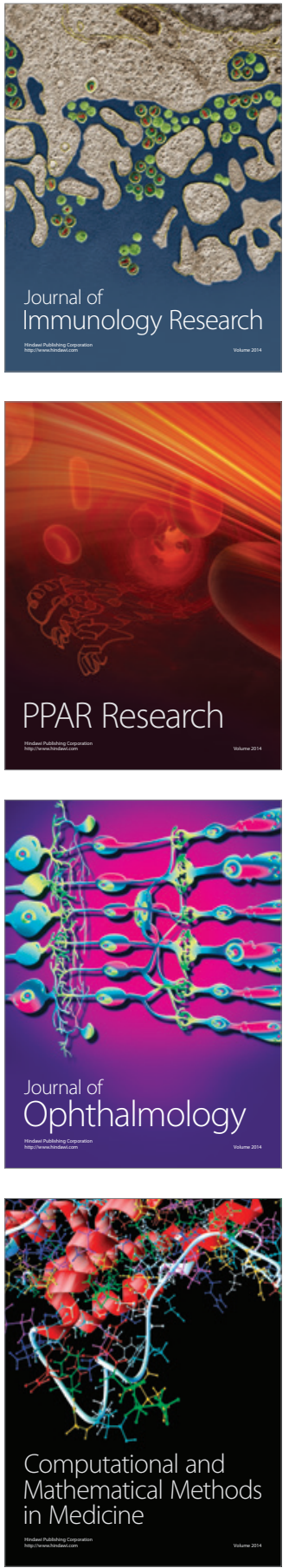

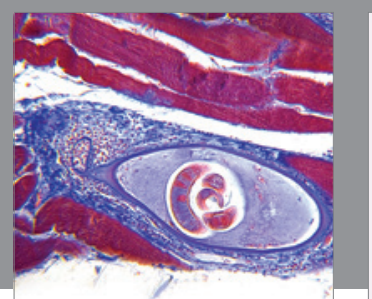

Gastroenterology Research and Practice

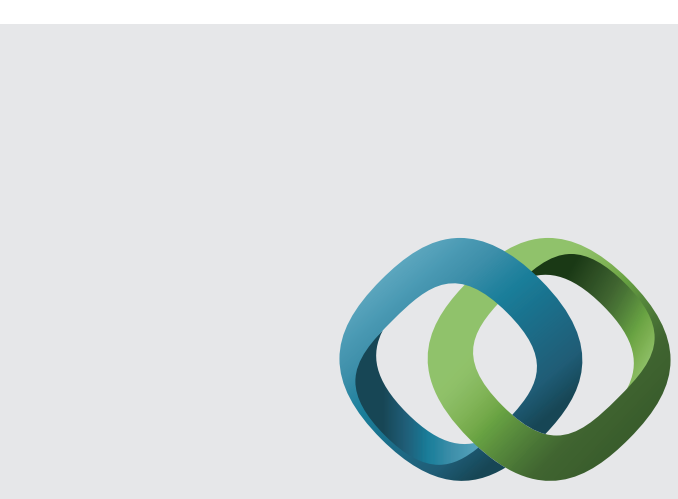

\section{Hindawi}

Submit your manuscripts at

http://www.hindawi.com
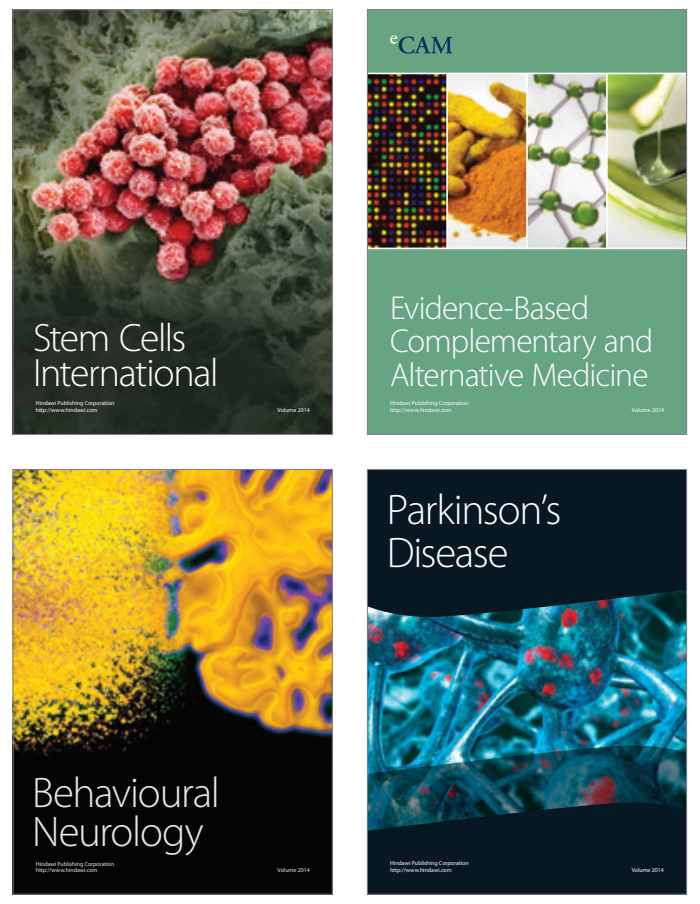
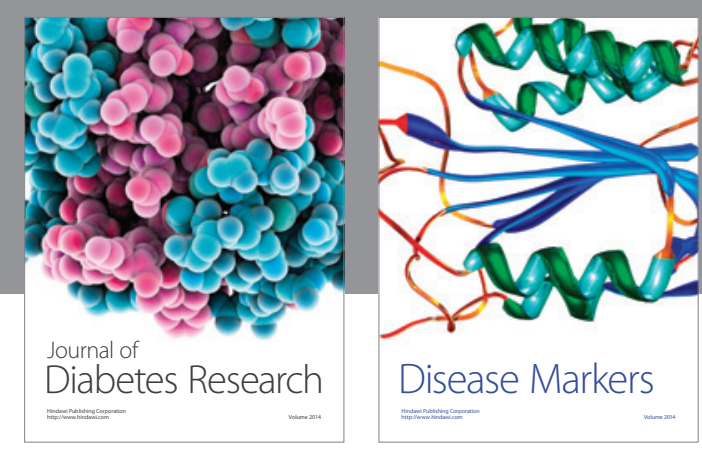

Disease Markers
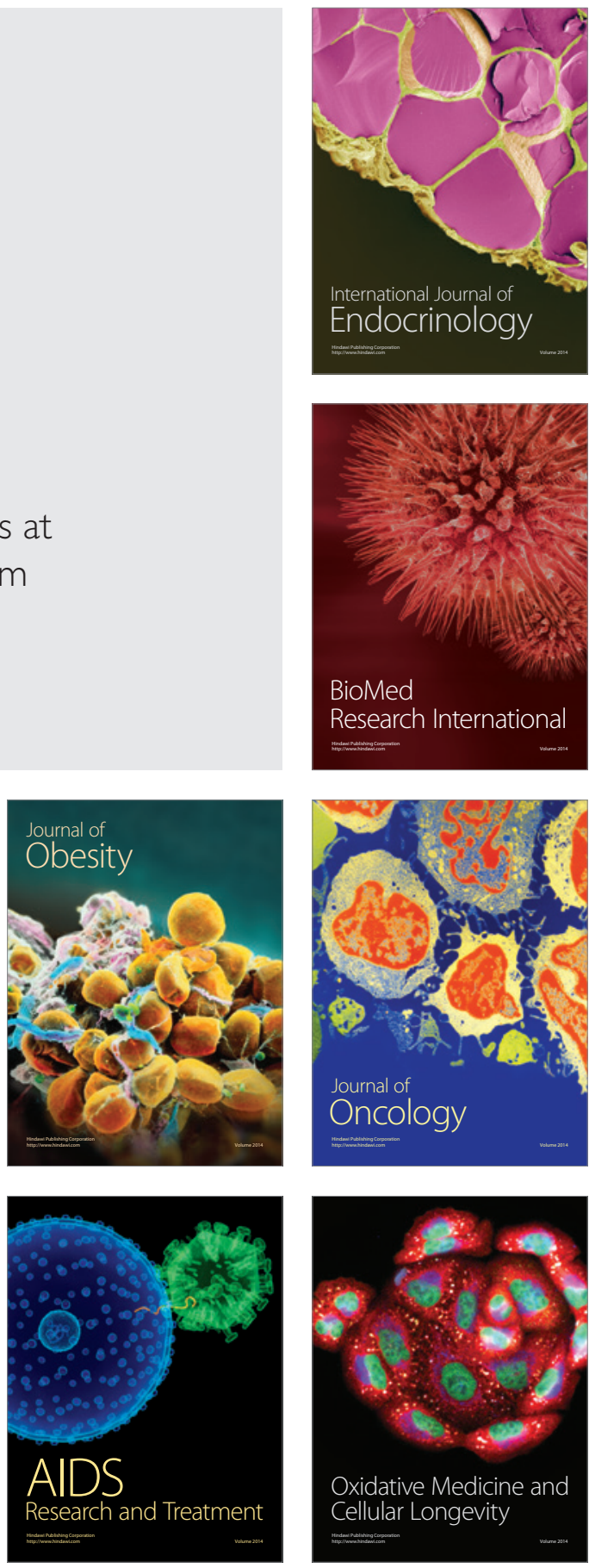